1. Lado Lado FL, Cabarcos Ortiz de Barrón A, Sánchez Aguilar MD, Rodríguez López I, Lorenzo Zúñiga V. Reacción de hipersensibilidad a la fenitoína. An Med Interna (Madrid) 2001; 18: 59-60.

2. Durán M, Danés I. Síndrome de hipersensibilidad por antiepilépticos. Med Clin (Barc) 2001; 116: 155-156.

3. Vittorio CC, Muglia JJ. Anticonvulsant hypersensitivity syndrome. Arch Int Med 1995; 155: 2285-2290.

4. Gómez-Criado MS, Ayani I, León-Colombo T, Ramos ML, Reneses MJ. Stevens-Johnson syndrome, toxic epidermal necrolysis and phenitoin. Factors linked to a higher risk. Rev Neurol 2004; 1-15; 38: 1056-60.

5. Carroll MC, Yueng-Yue KA, Esterly NB, Drolet BA. Drug-Induced hypersensitivity syndrome in pediatric patients. Pediatrics 2001; 108: 485-492.

6. Hamer HM, Morris HH. Succesful treatment with gabapentin in the presence of hypersensitivity syndrome to phenitoin and carbamazepine: a report of three cases. Seizure 1999; 8: 190-92.

6. Chopra S, Levell NJ, Cowley G, Gilkes JJ. Systemic corticosteroids in the phenitoin hypersensitivity syndrome. Br J Dermatol 1996; 134: 110912.

\section{Enfermedad celíaca en adultos. Un espectro clínico diferente}

\section{Sr. Director:}

La enfermedad celíaca o enteropatía sensible al gluten es un trastorno malabsortivo crónico del intestino delgado, causado por la exposición a una dieta con gluten en individuos genéticamente predispuestos. Aunque tradicionalmente se ha considerado un trastorno pediátrico, actualmente la enfermedad se diagnostica más en la edad adulta. En muchas ocasiones existen formas silentes o inadvertidas durante la infancia, pero otras veces se manifiesta "de novo" en sujetos adultos genéticamente predispuestos. Recientemente han sido diagnosticados en nuestro servicio 3 pacientes con distintas formas clínicas de presentación.

Caso 1: Mujer de 25 años de constitución asténica, que 2 meses antes de acudir a consulta comienza con dispepsia esporádica, con vómitos postprandiales y algún despeño diarreico, incluso nocturno, sin moco ni sangre. Refiere pérdida transitoria de $4 \mathrm{~kg}$ de peso, sin fiebre ni síndrome constitucional. En la analítica, destacaba Hb 13.6 g/dL, VCM 86.5 fL, L 9660/uL ( con fórmula normal), Fe $98 \mu \mathrm{g} / \mathrm{dL}$, ferritina normal, TSH y T4L normales, colesterol $179 \mathrm{mg} / \mathrm{dL}$, $\gamma$ Globulinas $20.5 \%$, Ca $8.18 \mathrm{mg} / \mathrm{dL}$, P 4.6 mg/dL, GOT 67 UI/L, GPT 53 UI/L, GGT y FA normales. Las serologías VHA, VHB y VHC resultaron negativas. El coprocultivo detectó sólo flora saprofita y el examen parasitológico en heces fue negativo. Por la alteración de la bioquímica hepática se realizó ecografía abdominal, donde se objetivaron esteatosis hepática, mínima cantidad de ascitis, asas intestinales dilatadas y adenopatías retroperitoneales, por lo que se realizó TAC abdominal, que confirmó la existencia de múltiples adenopatías mesentéricas y retroperitoneales menores de $1 \mathrm{~cm}$, con un bazo normal. Por la sospecha de linfoma intestinal se realizó tránsito intestinal, con datos radiológicos compatibles con malabsorción. Por este motivo se solicitaron anticuerpos anti-gliadina (Ig G $173(\mathrm{~N}<16)$ y Ig A $98(\mathrm{~N}<3) \mathrm{U} / \mathrm{L})$ y endoscopia digestiva alta, que mostró mínima hernia de hiato, bulbo duodenal normal y pliegues de segunda porción duodenal aplanados, cuyo examen histológico demostró atrofia subtotal de las vellosidades.

Caso 2: Mujer de 31 años con una hermana diagnosticada de enfermedad celíaca. Es remitida para estudio de ferropenia restistente a terapia sustitutiva. Se encuentra asintomática, sin alteración del ritmo intestinal. En la analítica destaca $\mathrm{Hb}$ de 12.4 $\mathrm{mg} / \mathrm{dL}$, con VCM de $89 \mathrm{fL}$, hierro sérico $41 \mathrm{mg} / \mathrm{dL}$, Ferritina 15
ng/mL, TSH y T4L normales, Calcio y fósforo normales. Las enzimas hepáticas eran normales, pero mostraba títulos de anticuerpos Anti transglutaminasa tisular mayores de $100(\mathrm{~N}<7)$ U/L. La endoscopia realizada mostró esófago y estómago normales, bulbo duodenal normal, con leve engrosamiento de pliegues de $2^{\text {a }}$ porción. La histología de los mismos diagnosticó atrofia parcial intensa de las vellosidades.

Caso 3: Mujer de 47 años sin antecedentes de interés, salvo diarrea episódica autolimitada, que consulta por pérdida de $12 \mathrm{~kg}$ de peso en los últimos 6 meses, y dolor abdominal intenso, tipo cólico, en mesogastrio, con sensación de distensión abdominal. Presenta deposiciones frecuentes y abundantes, adherentes y de color claro. En la analítica presentaba Hb $13.2 \mathrm{mg} / \mathrm{dL}$, VCM 87 fL, hierro sérico $36 \mathrm{mg} / \mathrm{dL}$, ferritina $20 \mathrm{~g} / \mathrm{dL}$. Por la alta sospecha clínica de celiaquía se solicitaron títulos de anticuerpos Ig A anti transglutaminasa tisular, que resultaron de $260 \mathrm{U} / \mathrm{L}$. La endoscopia fue normal hasta segunda porción, las biopsias duodenales fueron informadas de atrofia parcial intensa de las vellosidades.

La enfermedad celíaca es un trastorno frecuente, con prevalencia no totalmente conocida, pues depende de los criterios diagnósticos empleados, que en los países desarrollados se ha incrementado 10 veces en los últimos 50 años (1), en gran medida por el diagnóstico de formas subclínicas u oligosintomáticas. Cada vez se diagnostican más casos en pacientes adultos: en ocasiones son formas silentes o inadvertidas durante la infancia, pero otras veces se trata de manifestaciones "de novo" en la edad adulta. Por este motivo, muchos autores comienzan a considerar en la actualidad a la celiaquía una enfermedad propia de esta época de la vida (2). A diferencia de las formas clásicas infantiles, cada vez son menos los casos diagnosticados en adultos que debutan con diarrea y síntomas de malabsorción debida a atrofia vellositaria intestinal, y por el contrario predominan las formas clínicas atípicas $(3,4)$. Entre estas se pueden presentar anemia y ferropenia (4), hipocalcemia o hipoalbuminemia aisladas, aumento de VSG de causa no aclarada, polimialgia reumática $(1,5)$, síndromes ansiosodepresivos, hiperamilasemias debidas a macroamilasemia, elevación de transaminasas o distintos trastornos neurológicos o dérmicos. Las mujeres premenopáusicas y los varones con osteopenia y osteoporosis deberían ser evaluados para descartar enfermedad celíaca (6), que también debiera ser excluída en algunos casos de infertilidad.

Por su polimorfismo clínico, la enfermedad celíaca del adulto plantea diagnóstico diferencial con diversos trastornos digestivos, como el sobrecrecimiento bacteriano, la enfermedad de Crohn, la intolerancia a proteínas de leche de vaca, el linfoma intestinal o el síndrome del intestino irritable. En este sentido resulta interesante descartar celiaquía en aquellos pacientes adultos con este último diagnóstico que no presentan mejoría con diversos tratamientos ensayados (7).

Los casos que comunicamos son distintas formas de presentación de esta enfermedad en la edad adulta, que afecta predominantemente a mujeres (4). Las tres pacientes descritas respondieron satisfactoriamente a la dieta exenta en gluten. En muchos casos de enfermedad celíaca en adultos los síntomas gastrointestinales son leves y poco evidentes, y hasta en un 40 $\%$ de casos están ausentes (2). Pese a que algunos autores han descrito alteraciones endoscópicas de la mucosa duodenal que hacen sospechar esta entidad $(2,8)$, en nuestra experiencia, y tal y como queda reflejado en nuestros casos, no podemos establecer un patrón endoscópico definido, por lo que la biopsia de la mucosa sigue siendo la clave para el diagnóstico ante un paciente con manifestaciones varias en el que consideremos esta posibilidad.

En conclusión, durante los últimos años hemos asistido a un cambio en el patrón clínico y epidemiológico de la enfermedad celíaca, de modo que en la actualidad podría ser considerada más una enfermedad multisistémica con afectación primaria intestinal que un trastorno malabsortivo crónico. 


\section{A. J. Lucendo Villarín, J. Martín Plaza, C. Comas Redondo}

Servicio de Aparato Digestivo. Hospital Universitario La Paz. Madrid

1. Green PHR. The many faces of celiac disease: Clínical presentation of celiac disease in the adult population. Gastroenterology 2005; 128: S74S78.

2. Dewar DH, Ciclita PJ. Clinical features and diagnosis of celiac disease. Gastroenterology 2005; 128: S19-S24.

3. Villamil Cajoto I, Capparrini Escondrillas A, Villacián Viñedo MJ, Otero Antón E, González Quintela A. Enfermedad celíaca del adulto. An Med Interna (Madrid) 2005; 22: 552-553.

4. Cabral Rodríguez R, Arrieta Blanco FJ, Vicente Sánchez F, Cordobés Martín FJ, Moreno Caballero B. Enfermedad celíaca oligosintomática del adulto. An Med Interna (Madrid) 2004; 21: 599-601

5. Ojetti V, Nucera G, Migneco A, Gabrielli M, Lauritano C, Danese S et al. High prevalence of celiac disease in patients with lactose intolerance. Digestion 2005; 71: 106-110.

6. Madridano O, Lorenzo A, Fernández C, Arnalich F, Vázquez JJ. Enfermedad celíaca del adulto. An Med Interna (Madrid) 1998; 15: 327-333.

7. Treem WR. Emerging concepts in celiac disease. Curr Opin Pediatr 2004; $16: 552-559$

8. No more biopsy in the diagnostic work-up of celiac disease. Gastrointest Endosc 2005; 62: 119-121.

\section{Síndrome general, como presentación de un absceso pulmonar por Streptococcus pneumoniae}

\section{Sr. Director:}

El perfil clínico de presentación de la neumonía neumocócica es bien conocido: fiebre, escalofríos, tos con expectoración purulenta y dolor torácico pleurítico. Existen factores de mal pronóstico en su evolución: edad avanzada, bacteriemia, esplenectomía, afectación multilobar, leucopenia, ictericia, complicaciones extrapulmonares o pleuropulmonares. En particular, se observa derrame pleural en el $40 \%$ de las neumonías por este germen, evolucionando sólo un $2 \%$ a empiema. El absceso pulmonar es muy infrecuente, debiendo hacer sospechar de infección anaerobia coexistente o anormalidad anatómica, como obstrucción bronquial, neoplasia o infarto pulmonar. En este caso, suele estar implicado el serotipo 3, el más virulento de los 84 serotipos. El mecanismo patogénico es a través de una neumonitis necrotizante, con intervención de toxinas producidas por el S. pneumoniae: neumolisina y autolisina. Presentamos el caso de un paciente varón de 47 años de edad, fumador de 20 paquetes/ año, y hábito enólico de $>80 \mathrm{~g} /$ día; que ingresó en nuestro centro por cuadro de tos no productiva, astenia, anorexia y pérdida de unos $4 \mathrm{~kg}$ de peso, así como sudoración nocturna profusa, de aproximadamente cuatro semanas de evolución, tras haber presentado gastroenteritis autolimitada. En la exploración física de ingreso, estaba hemodinámicamente estable, afebril, consciente y orientado, normohidratado, con palidez cutánea, sin adenopatías periféricas. Los tonos cardiacos eran rítmicos, sin soplos; la auscultación pulmonar evidenciaba una buena ventilación bilateral; el abdomen era blando y depresible, sin masas ni megalias, ni dolor. No presentaba edema en miembros inferiores. La analítica demostró leucocitosis $\left(20970 / \mathrm{mm}^{3}\right)$, con neutrofilia $(95 \% \mathrm{PMN})$, anemia (Hb 10,3, VCM 96.2), trombocitosis (573.000), VSG > 120, reticulocitos 2,1\%, FA leucocitaria 82, GOT 64, GPT 121, GGT 102, LDH 292, con resto de parámetros dentro de la normalidad. La radiografía de tórax, no aportó alteraciones relevantes. Ante la objetivación de fiebre durante los primeros días de ingreso, y las altera- ciones hematológicas, se decidió realizar un TAC toraco-abdominal (Fig. 1), que mostró, a nivel de segmento posterobasal de LII, una lesión paramediastínica de $8 \times 7$ x $5 \mathrm{~cm}$, que presentaba ángulos agudos con respecto al margen pleural y morfológicamente esférica, homogéneamente hipodensa en su interior, con márgenes bien definidos. No se demostraron otras lesiones pulmonares ni adenopatías mediastínicas. Se observó también un nódulo suprarrenal izquierdo homogéneo de $3 \mathrm{~cm}$ de diámetro, inespecífico. Se realizó drenaje percutáneo por vía posterior de la lesión descrita, guiado por TAC, obteniéndose una mínima cantidad de material blancoamarillento muy espeso, de apariencia purulenta, donde se aisló Streptococcus pneumoniae sensible a penicilina. El cultivo de anaerobios, Löwenstein y hemocultivos, fueron negativos. Se instauró antibioterapia con ampicilina, y al cabo de una semana, se realizó nuevo TAC de control, objetivándose mejoría evidente de la lesión referida, con reducción significativa del tamaño y contenido de la colección. La neumonía neumocócica es la causa más importante de neumonía comunitaria severa. Uno de los factores de riesgo asociados con alta mortalidad es el enolismo crónico (1). Raramente, el Streptococcus pneumoniae es considerado un agente etiológico de neumonía cavitada o necrotizante. Cuando es así, suelen coexistir alteraciones inmunológicas o anatómicas (obstrucción bronquial, neoplasia o infarto pulmonar) o coinfección con anaerobios (2), junto con factores determinantes de la virulencia del germen: rápida multiplicación, acúmulo de polisacáridos capsulares (sobre todo, el serotipo 3), inhibición de la fagocitosis, producción de toxinas. Desde el punto de vista radiológico, el nivel hidroaéreo (3) de un absceso pulmonar suele observarse en la radiología simple de tórax; pudiendo extenderse a la pleura, formando ángulos agudos en contacto directo con ella. Más de un tercio de los abscesos de pulmón, pueden acompañarse por un empiema (4). El diagnóstico puede resultar difícil, pues sólo se aisla $S$. pneumoniae en esputo en un $50 \%$ y los hemocultivos son positivos en solo un $25 \%$. Por ello, muchas veces se hace necesario el abordaje a través de punción transtorácica, como fue en el caso presentado.

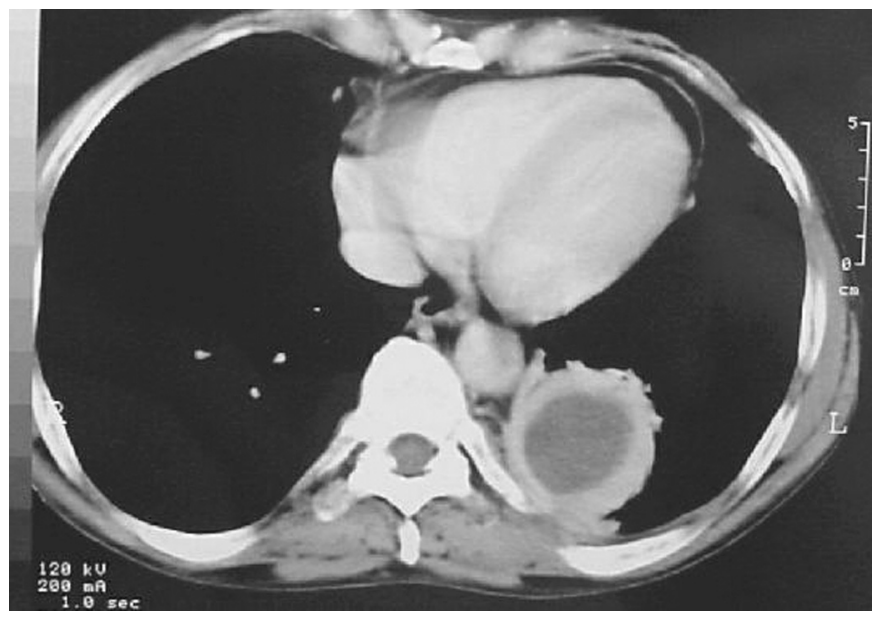

Fig. 1. TAC toracoabdominal.

H. Álvarez Díaz, F. Carrasco Sanz, I. Suárez Bonome', V. Trasancos Buitrago

Servicio de Medicina Interna y ${ }^{\prime}$ Radiología. Complejo Hospitalario Arquitecto Marcide-Profesor Novoa Santos. Ferrol, A Coruña

1. Campbell GD. Revisión de la neumonía adquirida en la comunidad: Pronóstico y aspectos clínicos. Clin Med NA 1994; 5: 1063-1077.

2. Leatherman JW, Iber C, Davies SF. Cavitation in bacteremic pneumococcal pneumonia. Causal role of mixed infection with anaerobic bacteria. Am Rev Respir Dis 1984; 129: 317-321. 